\title{
Analysis of Lifelong Physical Education Thought and Physical Education Teaching Reform in Colleges and Universities
}

\author{
Zheng Rongting \\ Yunnan University of Business Management, Kunming, Yunnan 650106, China
}

Keywords: Lifelong physical education; college physical education; teaching reform; countermeasures

\begin{abstract}
Lifelong education not only meets modern students' psychological needs and physical characteristics, but also has great significance for their physical quality and comprehensive quality. However, many colleges and universities are not mature enough in carrying out physical education at present, which has not only failed to give full play to the educational role of schools, but has had some adverse effects. This paper analyzes the problems existing in the reform of physical education in colleges and universities, and combines the idea of lifelong physical education with the reform of physical education in colleges and universities. The teachers of physical education in colleges and universities need to have the thought of lifelong physical education, continuously improve the education system and establish the supporting teaching mode. At the same time, we call on students to actively participate in extracurricular sports activities and gradually realize the reform of college physical education.
\end{abstract}

\section{Introduction}

With the continuous development of society, people also have a further understanding of physical education. It plays a very important role in our daily life. For example, it helps to improve our physical quality and physical and mental health. Colleges and universities should carry out physical education. The concept of lifelong education appears in our life as a new educational thought and has become a new direction for the development of contemporary sports. It can influence and play a role in people's thought in their lifetime and has important value to the development of individuals and society.

At present, the sports in our life mainly include leisure sports, fitness exercise, competitive sports, national sports, school physical education, and so on. The idea of lifelong physical education runs through these sports all the time. In the process of training students, colleges and universities must keep the lifelong physical education thought in the mind of every student according to the development of the times. Therefore, it is the goal that every university should pursue is to improve the physical education system, improve the overall quality of students and let physical education be integrated into everyone's life, so as to achieve the educational goal of lifelong physical education.

\section{The Brief Introduction of Lifelong Physical Education and College Physical Education}

Lifelong physical education is an international educational trend which began in the 1920s and prevailed in the 1960s. It argues that education should run through all stages of a person's life, not just in his childhood and adolescence. The expression "lifelong physical education" began in Britain in 1919 and was widely used in educational literature after the Second World War. In the 1960s, Paul Lengrand, the director of UNESCO's adult education bureau then, strongly advocated this idea. He suggested that there is no scientific basis for dividing life into two halves for hundreds of years, with the first half devoted to education and the second half devoted to work. He believed that receiving education should be a never-ending thing for a person from birth to death, and education should provide the necessary knowledge and skills in the best way when he needs. The idea of lifelong physical education is not only a means for students to achieve physical development during the college period, but also a solid foundation for their physical education after entering the society. Chinese educators have attached great importance to the concept of lifelong education since the late 1980s, but this concept was not put into practice at the first beginning. It did not stir a craze in China's sports circles until the $21^{\text {st }}$ century. 
Although there are many versions of the concept of lifelong physical education, the most accepted one so far is that: if a person receives professional physical education at school and persists in physical exercise or physical education in the future, he can obtain physical health as well as physical and mental pleasure and benefit from the process of physical exercise all his life, thus improving the quality of his life. From a scientific point of view, the development of a person's life does not conflict with lifelong physical education; instead, it is more in line with people's basic habits. One of its remarkable characteristics is that it can not only promote the improvement of students' sports performance, but also strengthen the all-round development of their morality, intelligence, physique and labor, which coincides with the idea of training all-round talents in colleges and universities. Moreover, lifelong physical education is never restricted by age. For children, physical education can make their bones stronger and help them grow taller; for older people, sports can relieve their work pressure and enhance their physical quality. The goal of lifelong physical education is to integrate the concept of lifelong physical education into everyone's life, so that people can change their way of life through exercise, change their values in practice, enhance their physical quality and improve their quality of life. In this sense, lifelong education is of great significance in the whole physical education. However, many colleges and universities now still copy the previous teaching mode when carrying out physical education, resulting in dull and boring physical education classes. For college students today, they have a strong ability of identification and information transformation, and the boring classroom can no longer meet their needs, so that they are always in a passive state in physical education. If the physical education that students receive at school lacks innovation and enthusiasm, they may lack the consciousness of physical exercise in their whole life, and then their physical quality and quality of life are really worrying.

\section{The Problems of Lifelong Physical Education in Colleges and Universities}

At present, there are great problems in the content and direction of physical education in colleges and universities, which makes the development of lifelong physical education very slow. Therefore, it is important to recognize these problems and thereby solve them better. First of all, people have weak awareness of lifelong physical education. In college physical education, both teachers and students don't know anything about lifelong physical education, mainly because schools have not applied ideological education of physical exercise on students and teachers. In the long-term physical education, schools generally focus the curriculum rather than the cultivation of students' interest, which leads to a fact that some students take part in physical education without realizing the importance of physical education. Secondly, the content of physical education is relatively single. The sports teaching contents most commonly used in colleges and universities are competitive sports activities. However, as modern sports become more and more competitive, individual sports cover many aspects, so they tend to be diversified in sports. Nowadays, Yoga, sports dance, badminton, martial arts and other sports have been greatly developing. At the same time, some traditional sports like gymnastics, basketball and volleyball suffer predicament in development due to the difficult exercise and single teaching contents. These traditional sports obviously do not meet the needs of modern college students, and they need fresh and interesting sports to arouse their enthusiasm. If they do not have enthusiasm, the participation in the PE class will be extremely reduced. Finally, physical education is not conducive to the formation of lifelong physical education in the curriculum. Many colleges and universities only offer physical education classes to freshmen and sophomores, and the class hours are short. Junior and senior students have heavy schoolwork, but it is precisely because of this that they need more physical exercise. Obviously, not exercising or taking short-time exercise each semester does not make lifelong physical education deeply rooted in the mind of students. 


\section{The Role and Significance of Physical Education Reform and Lifelong Physical Education Thought in Colleges and Universities}

\subsection{They help to improve students' enthusiasm for physical exercise.}

In the traditional teaching mode of physical education, students are required to pass the standard test in the physical education examination, and only after passing the test can they get corresponding credits. The biggest drawback of this traditional teaching mode is that it is difficult to fully mobilize students' enthusiasm for sports learning. They are in a passive state in the whole process. Most of the time, students may struggle to run in order to pass the exam, and sometimes they may even cheat in the exam to get credits. The essence of lifelong physical education thought is to let students be fond of sports to maintain their enthusiasm for sports. Getting rid of the shackles of traditional teaching mode can give students more choices, thus enriching their interest while increasing their independent choices.

\subsection{They help to cultivate students' awareness of lifelong sports.}

At present, the main problem is that the students do not establish the consciousness of lifelong sports after receiving education in the college or university and stop exercise after they enter the society. Colleges and universities not only fail to achieve the goal of lifelong physical education, but also make students more disgusted with physical exercise. However, both students and workers in schools must take health as their primary prerequisite in this highly competitive era. Therefore, colleges and universities should strictly adhere to the thought of lifelong physical education and further implement this idea, which will help cultivate students' awareness of lifelong physical education and improve their enthusiasm for exercise. Only by taking their physical and mental health as the main premise can people enrich their life.

\subsection{They are conducive to training students' fitness ability.}

Applying the lifelong physical education thought into physical education can enhance students' sports ability and enable them to improve their physical quality in various sports activities. The long-term development of physical education is not only conducive to the improvement of the physical education system in colleges and universities, but also can enrich the content of physical education to enhance the enthusiasm of students more effectively and make them aware of the importance of lifelong physical education, which can lay a solid foundation for the training of all-round talents in China.

\section{The Main Countermeasures to Promote Lifelong Physical Education and the Smooth Progress of Physical Education Reform in Colleges and Universities}

\subsection{It is important for college PE teachers to establish the idea of lifelong physical education.}

As the leader of the whole education system, the PE teachers are expected to cultivate more talents by exploring ways suitable for students. The teachers impart what they have learned and methods of interaction with others to students in a right way and then students understand what the teachers have taught by themselves. The teachers always play a role as a leader throughout this process[1]. Students are the main body in the whole process and get more enlightenment with the teachers' guidance. Therefore, teachers must constantly enrich their knowledge, enhance their overall quality and become role models for students to learn, and thereby they can better educate students from the ideological aspect, promote lifelong physical education and cultivate all-round talents. Lifelong physical education in colleges and universities is a long-term process, which requires not only training and education for teachers in schools, but also application of teaching by combining theory with practice, so as to ensure the dissemination of lifelong physical education thought.

\subsection{It is needed to improve the physical education system in colleges and universities.}

This measure is conducive to promoting the implementation of lifelong physical education model and the reform of physical education in colleges and universities. The first thing should be done is to stimulate students' enthusiasm. Teachers are supposed to give students frequent encouragement verbally. Teachers should give affirmation and praise to all students in the PE class. To the students who have slightly lagged behind, teachers should impart teaching contents according to their own characteristics, encourage them all the time and let students form healthy competition in a recognized environment. Improving 
students' sports ability is also necessary. The first step to better carry out a certain sports activity is to enhance participants' sports ability. Therefore, teachers should focus on training students' sports ability in the course of daily classes. In addition, when selecting sports courses, schools should respect students' interests instead of forcing students to choose appointed subjects. Teachers must pay more attention to the improvement of students' professional skills while cultivating their sports ability[2]. Finally, teachers should take students as the main body, attach importance to cultivating students' autonomous learning ability, and promote them to face study with a positive attitude. To sum up, the overall quality of teachers is the decisive factor in the teaching effect, so it is critical to strengthen the construction of teachers, take appropriate measures to cultivate them and build a perfect team of teachers. In addition, it is necessary to establish and improve the competition mechanism to make PE teachers face the market and students' choices, allowing students to choose their favorite courses and enabling teachers to take up jobs through competition. Only in this way can outstanding teachers with true skills and genuine knowledge give full play to their role.

5.3 There is a need to establish a teaching model suitable for lifelong physical education. A good teaching mode is the first step to the success of education, and only an appropriate teaching mode can promote the development of lifelong physical education. The in-and-out-of-class integration mode and the sports-style teaching mode are the two main teaching modes. The teaching mode of in-and-out-of-class integration refers to the integration of physical education with students' extracurricular physical activities to achieve the integrity of physical education in colleges and universities. The advantage of this mode is that it can maintain the continuity of the whole teaching activity, ensure close connection between classes and extracurricular activities and enable students to form the thought of lifelong education virtually. The latter teaching mode refers to the teacher making feasible strategies according to each student's own characteristics by stimulating their interests and hobbies, realizing teaching students in accordance with their aptitude. Teachers' special education methods can not only enable students to master more sports knowledge, but also urge them to continue for a long time and gradually form a habit. The change of teaching mode will certainly make students feel different, but the new teaching mode aims at teacher-student interaction, forming resonance and achieving win-win results. This kind of teaching mode will have some impacts on the traditional mode, but the impact can enhance students' thinking model and will be more in line with the direction of teaching development in the new era.

\subsection{Schools should call on students to actively participate in extracurricular sports activities.}

Lifelong physical education includes pre-school physical education, school physical education and social physical education. Therefore, colleges and universities should organize extracurricular sports activities, cultivate students' lifelong sports awareness through various ways and channels, and help them continuously improve their own exercise ability in extra-curricular sports activities, so as to prepare for the development of lifelong sports education.

\subsection{The curriculum and teaching materials should meet the requirements of lifelong physical education.}

Only scientific curriculum is the best tool for education, so colleges and universities should thoroughly implement the idea of lifelong physical education. Curriculum arrangement cannot be based on grade alone. Specifically speaking, senior and senior students also need appropriate arrangements. The course content should be renovated regularly and highlight creativity, and a flexible, rich and personalized teaching material system with lifelong physical education as the main line should be established so as to improve students' enthusiasm in essence[3]. It is needed to adopt a variety of teaching methods and means in teaching activities to stimulate students' interest in sports, cultivate their habit of physical exercise, improve their physical exercise ability and lay a solid foundation for their lifelong physical education. However, when setting up the contents of the teaching materials, it is necessary to take the physical condition of contemporary college students into account. The development of colleges and universities cannot be separated from the implementation of lifelong physical education. In other words, the development of colleges and universities and lifelong physical education are closely tied to each other. 


\section{Conclusion}

Physical education in colleges and universities is a systematic and complex project, which requires continuous innovation of knowledge theory and teaching mode. Colleges and universities must carry out lifelong physical education to further promote the reform of physical education, improve the overall physical quality of students and enhance their enthusiasm and initiative to participate in physical activities, so that they can establish the concept of lifelong sports and develop their habit of lifelong sports. The author hopes the views mentioned in this paper can play a good role in the current physical education in colleges and universities in China.

\section{Reference}

[1] Si Huifeng. Analysis of Lifelong Physical Education Thought and College Physical Education Reform [J]. Speed Reading, 2017(8).

[2] Chen Dachun. Analysis of College Physical Education Reform Based on Lifelong Physical Education Thought [J]. Modern Women, 2013 (9).

[3] Shu Jun. Analysis of Teaching Reform of College Physical Education Based on the Idea of Lifelong Physical Education [J]. Journal of Jiamusi Education Institute, 2013(10). 